\title{
Analysis of stress and deformation fields of shape complex beams
}

\author{
Miroslav Pástor ${ }^{1}$, Pavol Lengvarský ${ }^{1, *}$ \\ Department of Applied Mechanics and Mechanical Engineering, Faculty of Mechanical Engineering, \\ Technical University of Košice, Letná 9, 04200 Košice, Slovakia
}

\begin{abstract}
In this paper is investigated the analysis of stress and deformation fields of shape complex beams. The shape complex beams are made from load-bearing sheet (trapezoidal sheet) circumferentially connected with strips of sheet metal, these beams are a substitute for more complex and heavier beams. The numerical analysis with static load are performed for these beams. The effect of three different types of connections between load-bearing sheet and strips of sheet metal is investigated. The first type of connection is represented by the trapezoidal sheet perfectly welded to the strips of sheet metal, the second type of connection is represented by the trapezoidal sheet welded to the strips of sheet metal only on the base sides of the trapezoidal sheet. The third one is represented by point welds. The stress and deformation fields for all types of the connections are compared and the suitable variant is chosen.
\end{abstract}

Keywords: stress, deformation, beam, contact, container

\section{Introduction}

Start of development of thin-walled structures (beams) can be traced back to the 19th century, due to the rapid development of the industry, it was necessary to create large-scale buildings, structures and facilities, when conventional design methodologies together with traditional materials could not be always applied. Various types of beams can be made from structural elements, from full to various hybrid beams. The use of a specific beam depends on many static, structural, manufacturing factors and requirements. The current trend is to use different types and shapes of beams and create from them a complex truss. Nowadays, the trend of optimal utilization of design and material is used for mass and cost reduction. This creates opportunities for new ideas of design structural elements. New ideas can also include trapezoidal beams, where the trapezoidal sheet is connected circumferentially with the strips of sheet metal. These beams can be used as part of roof construction, which can be used to protection of shipping containers before the different weathers [1].

The carrying frame of the containers is made from welded closed cylindrical tubes with the thickness $3 \mathrm{~mm}$. The covering of container is made from panels of profiled alloy steel sheets with thickness from $1.5 \mathrm{~mm}$ to $2 \mathrm{~mm}[2,3]$. The alloy steel is also called Corten steel, it is characterized by high resistance to weathering. The containers (Fig. 1) are

\footnotetext{
* Corresponding author: pavol.lengvarsky@tuke.sk

Reviewers: Radim Halama, Marcin Kubiak
} 
designed for ship transportation, they are the cheapest and fastest way to create inexpensive warehouses. They can to serve as low-cost modular skeletons for creating residential, nonresidential, underground and above-ground objects. The ship containers can be use as mobile polyfunctional objects, halls offices, objects for housing or business etc. (Fig. 2). The main advantage of shipping containers is they higher resistance to weathering, fire resistance, safety and lock ability. The containers are stackable, mobile without needing to unload contents.

a)

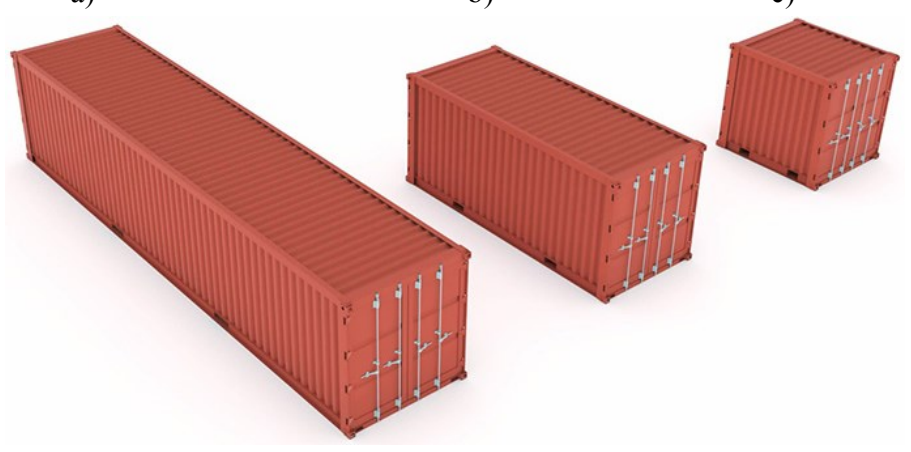

Fig. 1. Ship container a) $40^{\prime} \mathrm{DC}$ with length $12 \mathrm{~m}$, b) $20^{\prime} \mathrm{DC}$ with length $6 \mathrm{~m}$ and c) $10^{\prime} \mathrm{DC}$ with length $3 \mathrm{~m}$
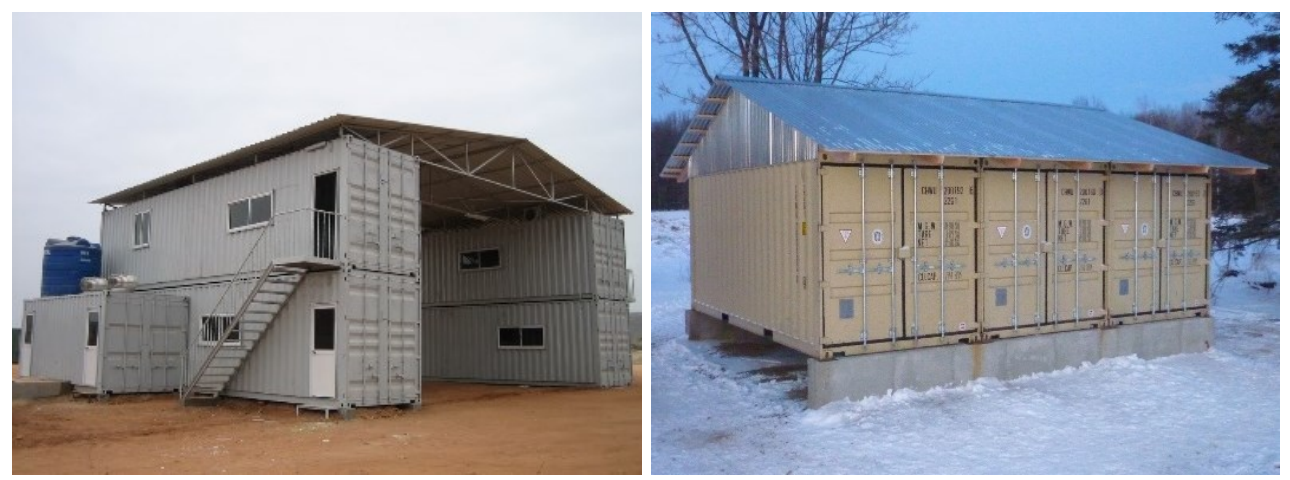

Fig. 2. Mobile polyfunctional objects

The structural design of the shape complex beams is investigated in this paper. The beams are carrier elements of the roof structure with dimensions identical with ship container (20'DC) of length $6058 \mathrm{~mm}$, width $2438 \mathrm{~mm}$, height $2591 \mathrm{~mm}$, mass $2200 \mathrm{~kg}$ and load capacity $24800 \mathrm{~kg}[2,3]$. The design of the beams is based on the required beam length, the minimum height of the lower end and the minimum slope. The shape complex beams are made from load-bearing sheet (trapezoidal sheet) circumferentially connected with strips of sheet metal, these beams are a substitute for more complex and heavier beams. The effect of three different types of connections between load-bearing sheet and strips of sheet metal is investigated. Modern means of numerical modelling (finite element method) are used for design and optimization the beam [4-6].

\section{Finite element model of shape complex beam}

The shape and the basic dimensions of the designed beam are shown in Fig. 3. The beam web is made from a trapezoidal steel sheet with thickness $0.7 \mathrm{~mm}$ and the beam flanges are 
made from strips of sheet metal with thickness $5 \mathrm{~mm}$. The ends of beam are closed with the same strips of the sheet metal. The reinforced strips of sheet metal are used $100 \mathrm{~mm}$ from the ends of the beam.

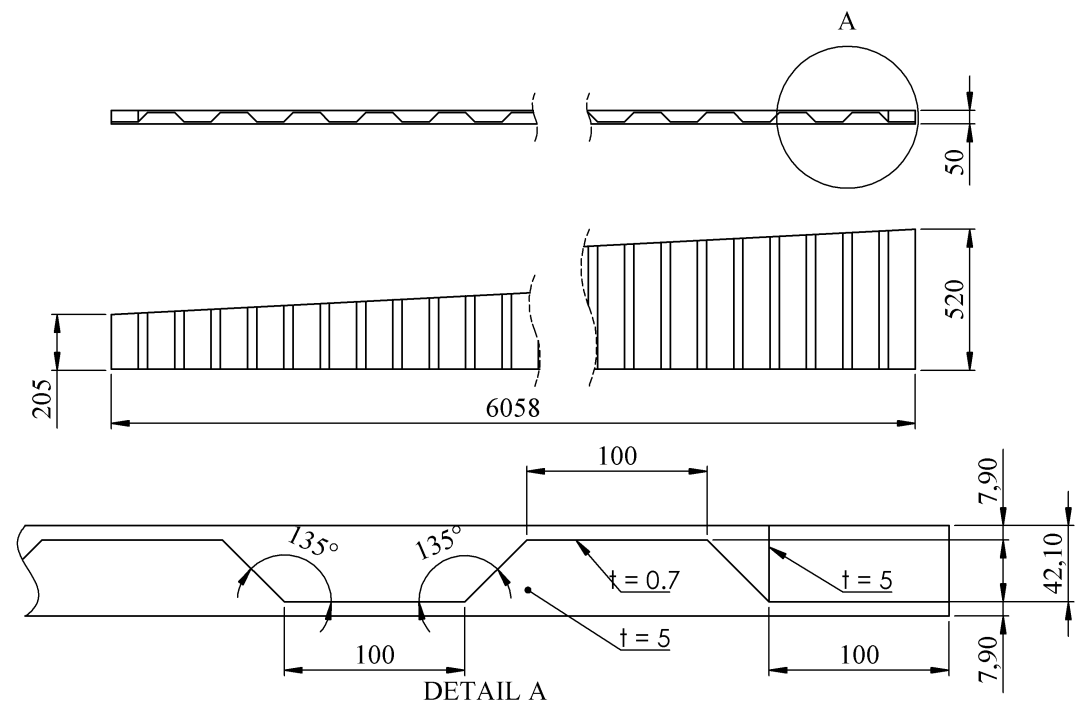

Fig. 3. Basic dimensions of designed beam

The model of beam is prepared in CAE software, where the material properties, contacts between parts, boundary conditions, loads are applied on the model. The beam is made from the steel KOHAL 280 with the yield strength $280 \mathrm{MPa}$ and the maximum tensile strength $410 \mathrm{MPa}$. The steel is suitable for non-structural presswork and for forming. The three variants of the boundary conditions are applied to connection the trapezoidal sheet with circumferential strips of sheet metal. The first type of connection is represented by the trapezoidal sheet perfectly welded to the strips of sheet metal (Fig. $4 \mathrm{a}$ - red dashed line). The second type of connection is represented by the trapezoidal sheet welded to the strips of sheet metal only on the base sides of the trapezoidal sheet (Fig. 4b). The third one is represented by the point welds (Fig. 4c). The connections are made only as bonded contact because the effect of the welds and stresses in the welds are not studied.

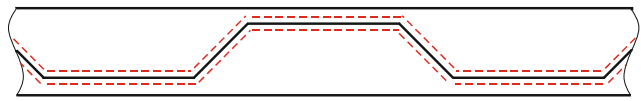

a)

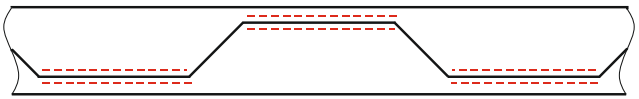

b)

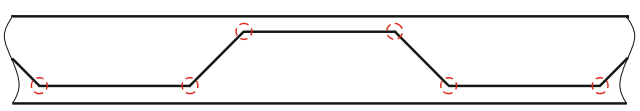

c)

Fig. 4. Three variants of the connection of the trapezoidal sheet with strips of sheet metal

The top strip of sheet metal is loaded by the pressure with value $P=25000 \mathrm{~Pa}$, the load is computed using the Slovak Technical Standard (STN EN 1991-1-3) [7]. The self-weight is applied too to the beam. The beam is on both ends fastened with a bolt and is supported by steel plate as part of container. The degree of freedom in the direction perpendicular to the beam on the top flange is taken every $1000 \mathrm{~mm}$, this restriction represents the connection of the beam with the next beam and the support for the roofing sheet. Finally, the numerical computations are done for the finite element model consist from shell 
elements with maximum size of element $20 \mathrm{~mm}$. The fields of equivalent stresses for the three variants of the connection of the beam web with the beam flanges are shown in Figs. $5-7$. The detailed views of fields of equivalent stresses of beam for all variants are shown in Figs. 8-10.

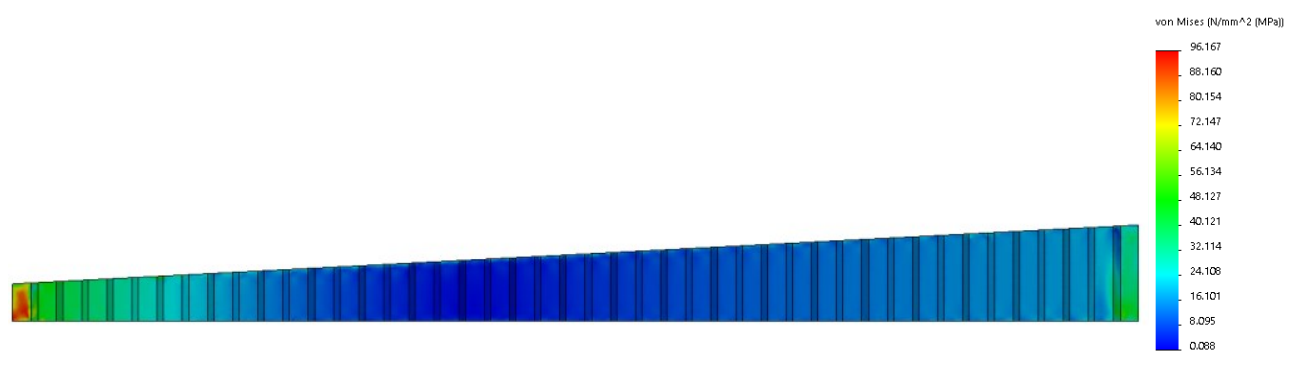

Fig. 5. Field of equivalent stresses of beam for the first variant

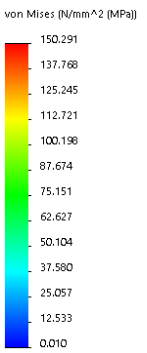

Fig. 6. Field of equivalent stresses of beam for the second variant

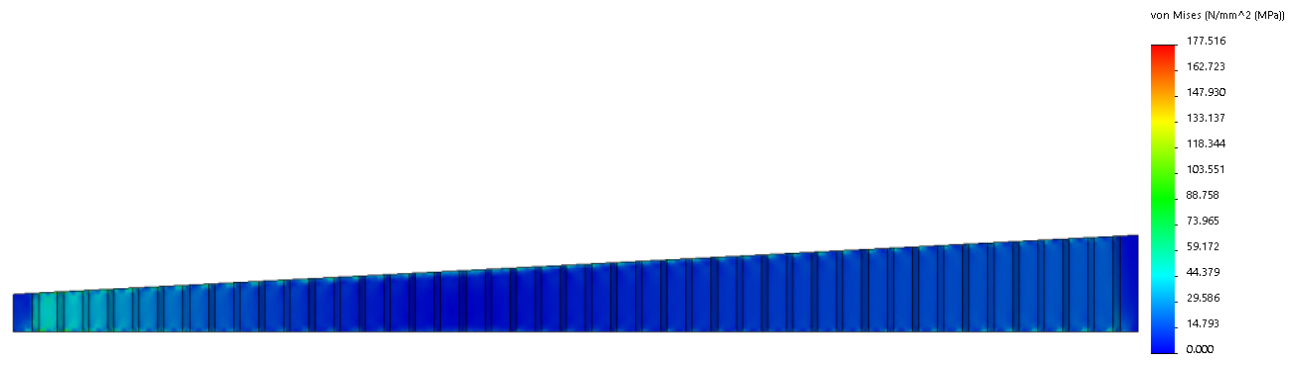

Fig. 7. Field of equivalent stresses of beam for the third variant

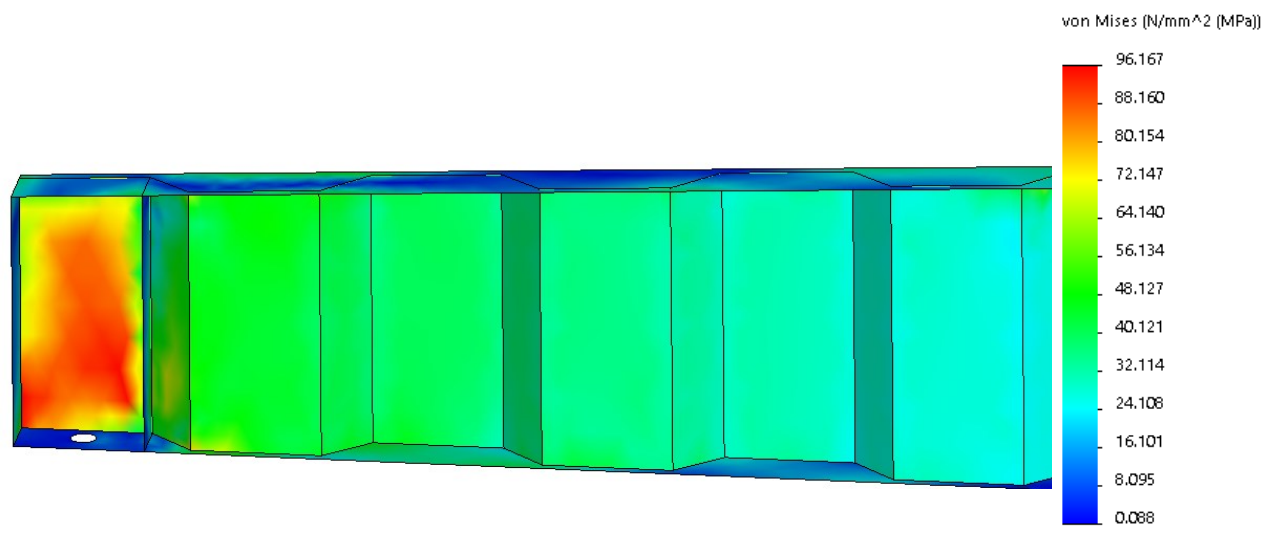

Fig. 8. Detail of field of equivalent stresses of beam for the third variant 


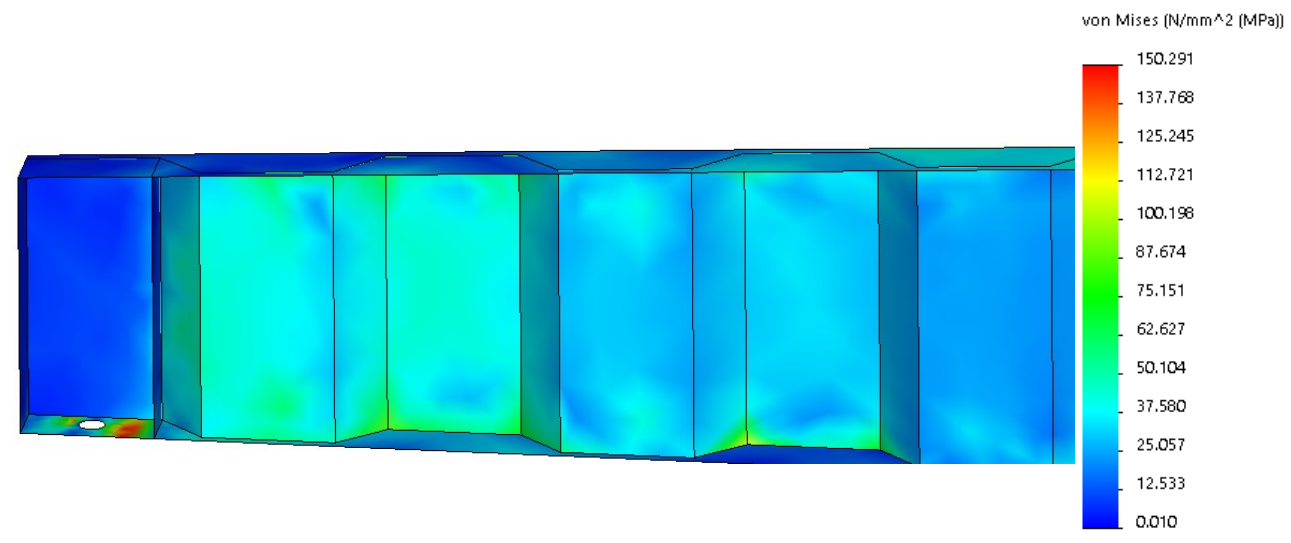

Fig. 9. Detail of field of equivalent stresses of beam for the third variant

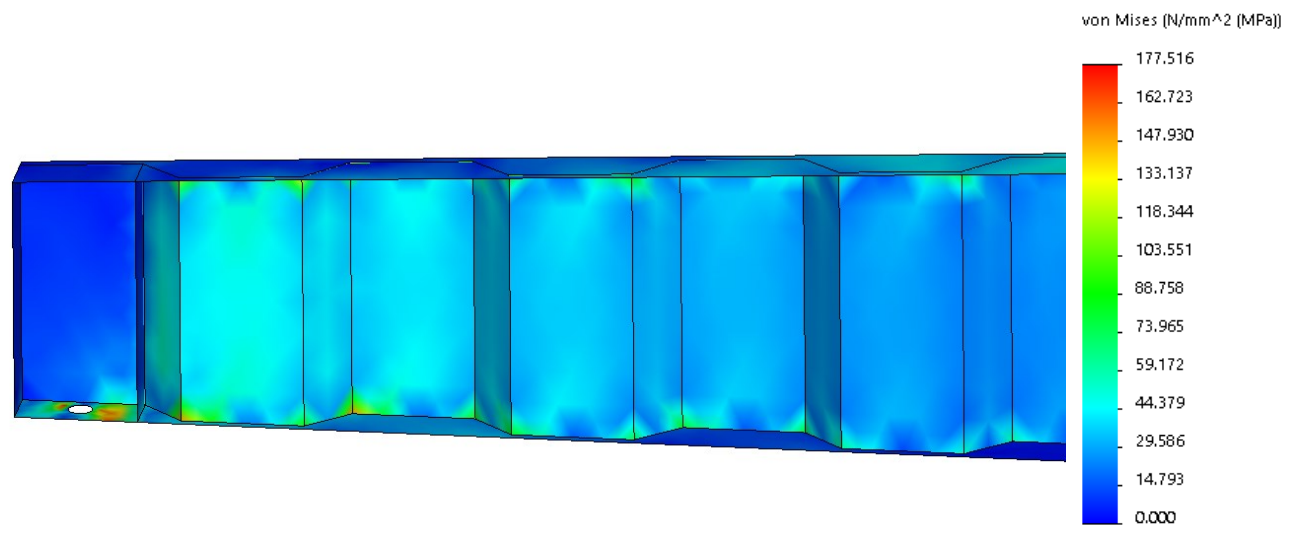

Fig. 10. Detail of field of equivalent stresses of beam for the third variant

The displacements of points of the structure in $Z$ direction (perpendicular to the ground) for the first variant are shown in Fig. 11. The shape of the second and third variants after deformation is the same as the first variant, only the value of the maximum displacement is different.

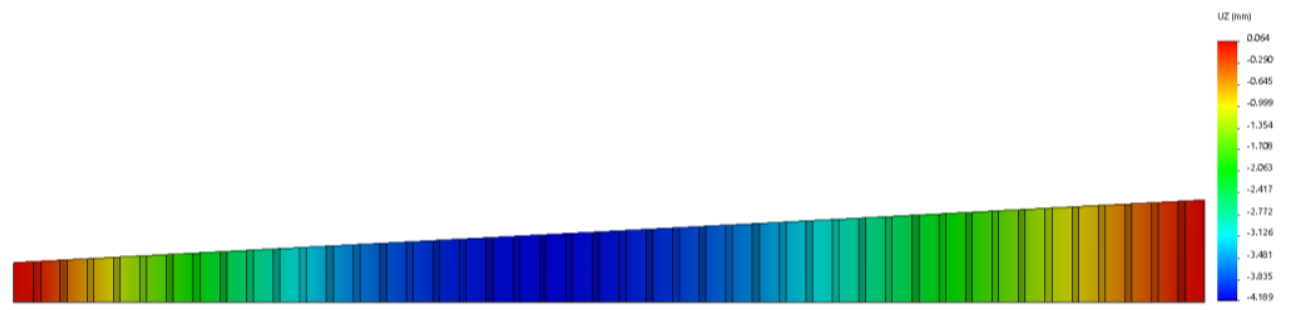

Fig. 11. Displacements of points of beam for the first variant

The computed maximum equivalent stresses and displacements in the $Z$ direction for the all variants are given in Table 1. 
Table 1. Computed parameters of beam

\begin{tabular}{|c|c|c|}
\hline Variant & $\begin{array}{c}\text { Equivalent stress } \\
\sigma_{\max }[\mathrm{MPa}]\end{array}$ & $\begin{array}{c}\text { Displacement in } \boldsymbol{Z} \\
\text { direction } \\
\boldsymbol{w}_{\max }[\mathbf{m m}]\end{array}$ \\
\hline 1. & 96.167 & 4.189 \\
\hline 2. & 150.291 & 5.656 \\
\hline 3. & 177.516 & 4.673 \\
\hline
\end{tabular}

For the comparison, the numerical analysis of the beam with the trapezoidal sheet thickness equal $1 \mathrm{~mm}$ is performed for the all variants. The all other dimensions, parameters, boundary conditions and loads are considered to be the same. The results of computations are given in the Table 2.

Table 2. Computed parameters of beam

\begin{tabular}{|c|c|c|}
\hline Variant & $\begin{array}{c}\text { Equivalent stress } \\
\boldsymbol{\sigma}_{\max }[\mathrm{MPa}]\end{array}$ & $\begin{array}{c}\text { Displacement in } \mathbf{Z} \\
\text { direction } \mathbf{w}_{\max } \\
{[\mathrm{mm}]}\end{array}$ \\
\hline 1. & 87.552 & 3.851 \\
\hline 2. & 141.918 & 5.070 \\
\hline 3. & 165.505 & 4.458 \\
\hline
\end{tabular}

Based on the comparison of the achieved results from Tables 1 and 2 can be said, that the all stresses are below as the Yield strength. From the point of view of the maximum equivalent stresses, the first variant is the best variant and the second variant is the worst variant. With the change of the thickness of the trapezoidal sheet from $0.7 \mathrm{~mm}$ to $1 \mathrm{~mm}$, the investigated parameters decrease but the total weight of the beam increases from $39.926 \mathrm{~kg}$ to $45.508 \mathrm{~kg}$, it represents $13 \%$ increase of mass.

\section{Conclusion}

The numerical computations of the three variants shape complex beam were investigated in this paper. The beam web was made from the trapezoidal sheet and the flanges were made from the strips of sheet metal. The all variants had the same dimensions, boundary conditions and loads. The connections between the beam web and flanges were varied for the variants. The first type of connection was represented by the trapezoidal sheet perfectly welded to the strips of sheet metal, the second type of connection was represented by the trapezoidal sheet welded to the strips of sheet metal only on the base sides of the trapezoidal sheet. The third one was represented by the point welds. The three variants of connection were used in the numerical simulations but in real carrier structures can be used only the first two variants. The computations were done for the beam web with the thickness $0.7 \mathrm{~mm}$ and $1 \mathrm{~mm}$. With the change of the thickness of the beam web, the equivalent stresses decreased by $10 \mathrm{MPa}$ and the mass increased by $13 \%$. According to weld technology is better use the beam web with thickness $1 \mathrm{~mm}$ and the effect of the weight of the weld can be negligible.

This research was financially supported by Slovak Grand Agency through the grant number VEGA 1/0731/16 and KEGA 049TUKE-4/2017. 


\section{References}

1. M. Pástor, J. Bocko, T. Kula, C.S. Roszkos, Possibilities of Optimizing the Shape and Geometry of Castellated Beams Using Numerical and Experimental Modeling, Am. J. Mech. Eng. 4 (7), 357-362 (2016)

2. STN 26 9340, ISO freight containers series 1. Specification and testing. Basic regulations.

3. STN 299344 - ISO 1161, Containers ISO series 1. Corner fitting.

4. P. Paczos, P. Wasilewicz, E. Magnucka-Blandzi, Experimental and numerical investigation of five-layered trapezoidal beams. Compo. Struct. 145, 129-141 (2016)

5. J. Nagler, Pitting corrosion investigation of cantilever beams using F.E. method. Acta Mech. Slovaca. 16 (4), 12-19 (2012)

6. O. Tusnina, A finite element analysis of cold-formed Z-purlins supported by sandwich panels. Appl. Mech. Mater. 467, 398-403 (2013)

7. STN EN 1991-1-3, Eurocode 1. Actions on structures, Part 1-3: General actions. Snow loads. 